\title{
Blood Treatment
}

National Cancer Institute

\section{Source}

National Cancer Institute. Blood Treatment. NCI Thesaurus. Code C15657.

General term for hemodialysis, plasmapheresis, blood transfusions, and related procedures involving autologous removal, alteration, and replacement of patients' blood or blood components. 